\title{
Ecology, Environment, Sustainability: The Development of the Environmental Movement in Israel ${ }^{1}$
}

\author{
Benny Furst \\ Ministry of Environmental Protection, Jerusalem, Israel
}

\begin{abstract}
The article surveys the development of the environmental movement in Israel from the establishment of the state through the present day. Based on trends and transformations in the institutional planning system, it appears that activism by environmental movement organizations in Israel can be divided into three sub-periods: the establishment period, marked by the Sharon Plan, the founding of the Society for the Protection of Nature in Israel and MALRAZ - Council for the Prevention of Noise and Air Pollution in Israel, and the enactment of the Kanovitch Law and the National Parks and Nature Reserves Law (1963). The next phase of institutionalization is characterized by the establishment of designated institutional bodies - the Nature Reserves Authority, the National Parks Authority and the Environmental Protection Service, and their integration into the national planning system. The institutionalization period concludes with the establishment of the Ministry of the Environment (1989) and the transition to the third period, sustainability. Prominent during this period is a trend toward multidimensional proactive environmental planning and policymaking, reaching across many areas and including extensive regulation. As far as environmental organizations are concerned, these three periods comprised a framework of cultural action in which they developed, acted and shaped environmental discourse and practice in Israel. Based on other studies, the article offers a model that illustrates the development of the environmental movement while emphasizing the interaction between individual actors, local organizing and national organizations. Finally, some characteristics and insights regarding activism by environmental organizations in Israel are suggested.
\end{abstract}

Keywords: environmentalism, environmental campaigns, environmental movement organizations (EMO's), sustainability

\section{Background}

Public activism in the environmental field in Israel has gained momentum over the last two decades, in terms of both the scope of such activism and the degree of its impact on public discourse and decision-makers. This finds expression in the plethora of organizations and bodies dealing with environmental issues in the country, which number today over a hundred, as well as in the sophistication of methods of action employed, as manifested in the professionalization of environmental knowledge, enhanced activist recruitment capacities, and inter-organizational coalition building (Karassin, 2001; Tal, 2011). Another salient trend in environmental

Benny Furst, Ph.D., Ministry of Environmental Protection, Israel.

Correspondence concerning this article should be addressed to Benny Furst, 30A Kubovy st., Jerusalem 9675742, Israel.

1 The present article is based on the introductory chapter of the author's doctoral dissertation on the political cultures of environmental movements in Israel. The research was conducted under the supervision of Professor Shlomo Hasson of the Department of Geography, Hebrew University of Jerusalem. 
activism over the last decade is an engagement with ethical and social aspects of environmental issues, such as sustainability principles and environmental justice, as opposed to nature and ecology preservation in the narrow sense, which was typical of the previous generation of environmental public activism (Rabinowitz, 2002). The increasing effectiveness of environmental organizations' campaigns shows that this is a phenomenon that meets the broad definition of a social movement:

collectivities acting with some degree of organization and continuity outside of institutional or organizational channels for the purpose of challenging or defending extant authority, whether it is institutionally or culturally based, in the group, organization, society, culture, or world order of which they are a part. $^{2}$

In a broader context, the environmental movement in Israel could be said to be part of the global environmental movement, and in fact part of the more general phenomenon of environmentalism. ${ }^{3}$ Figure 1 outlines the general context in which Israeli environmental organizations operate.

New Social Movements (NSM)

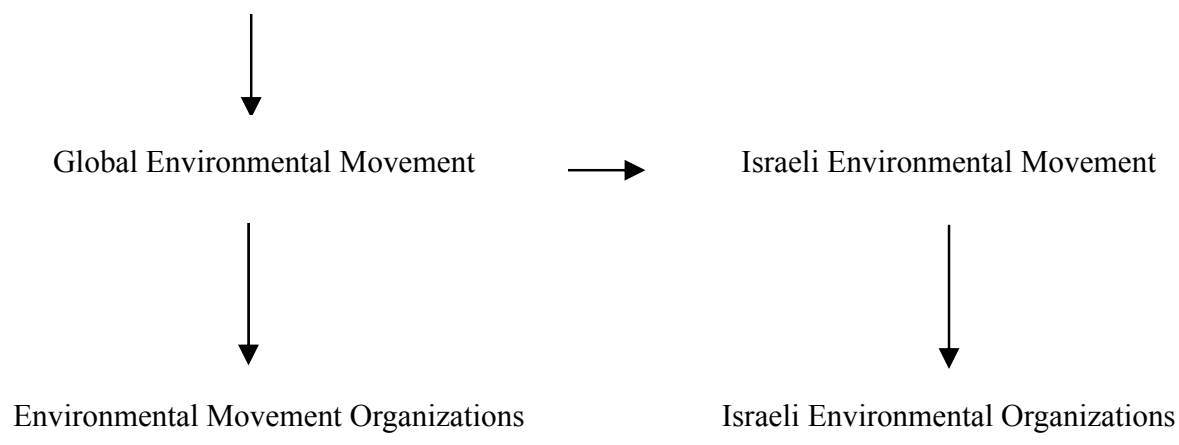

Figure 1. Israeli environmental organizations-General context.

The global environmental movement is the last "survivor" among the multitude of large-scale social movements that emerged beginning in the 1960s (Rootes, 2003). ${ }^{4}$ Today, having gained the perspective of several decades, the environmental movement can be said to have undergone two major trends: institutionalization and professionalization. Institutionalization is manifested primarily in the assimilation of not only some of the formal organizations but also many environmental concepts and issues into the political establishments of developed countries. With respect to professionalization, an increasing sophistication has occurred in everything related to the study of environmental problems, modi operandi and principally the infusion of science into the dynamics of the environmental system. As an outcome of these two trends, environmentalism comprises today an all-encompassing conceptual super-framework for the activities of thousands of NGOs dealing with environmental issues, which accordingly have come to be termed "Environmental Movement Organizations" or EMOs (Rootes, 1999). Scholar and environmental activist Paul

2 Definition according to Snow, Soule and Kriesi (2004: 11).

${ }^{3}$ It should be noted that the global environmental movement is a specific case of one of the new social movements (NMS) that emerged in developed countries beginning in the 1960s.

${ }^{4}$ Yet, over the last half decade we have witnessed global waves of protest on other issues, such as the demand for an alternative political order, social justice, the campaign for housing rights and quality of life, as well as social identities. Hence, the environmental movement is not the only dominant one. For a concise survey of the development of the global environmental movement, see Shperman, 2007. 
Hawken argues that quantitatively speaking there are approximately 30 thousand NGOs today dealing with environmental issues, and that if we include organizations dealing concurrently with issues of social justice and minority rights, their numbers soar to more than a hundred thousand (Hawken, 2007). ${ }^{5}$

The global environmental movement's major contribution has been the creation of a new culture, a "Green Culture," as Castells (1997) terms it, which has engendered new ways of thinking about everything concerning the interaction between human society and economy and the natural environment, while basing itself upon sustainable development principles. In view of his analysis of the global environmental movement according to the types of organizations and the nature of their activism, Castells determines that a significant difference exists between the organizations in terms of their collective identity, objectives and definition of the "enemy". An important binary distinction that Castells draws in this context is between "ecological" organizations and "environmental" organizations: while, from his sociological perspective, "ecological" organizations regard the human being as merely one element among many in nature, "environmental" organizations orient themselves to human collective behavior whose aim is to right wrongs done when the harmonious interaction between people and their natural environment is violated. This dichotomy also has significance from an ethical perspective, in the distinction between two approaches: the ecological justice approach, which grapples with the question of humankind's proper relation to the environment and natural resources in the narrow sense, and the environmental justice approach, which centers on the question of allocation of risks stemming from the exploitation of the environment and its resources (Hasson, 2009).

\section{The Environmental Movement in Israel as Mirrored in the Present Study}

Most of the studies to date that have dealt with environmental activities, Israel have focused on an empirical examination of the campaigns, their outcomes, and their effect on decision-makers. Thus, for instance, Gottleib (2004) examines the action dynamics, thought processes and organization of two of the most important environmental organizations in Israel (The Society for the Protection of Nature in Israel and Adam TevaV'Din) and their impact on coastal planning. His findings show, inter alia, that the organizations' action had a curbing effect at the beginning of the period studied (1997-2000) while later on a proactive effect was identified (2000-2003). The major difference stems from the types of activism employed: in this case, the campaign began with legal action, which is inherently reactive, and later evolved into action at the level of professional planning, which is proactive in nature.

An earlier pioneering study by Talias (1994), which examines two of the most important environmental campaigns of the 1980s in Israel, deals with the political and philosophical aspects of the case of the hydroelectric plant at Kfar Hanassi in the north and the plan to erect the "Voice of America" relay station in the Arava region. In it, Talias characterizes the two campaigns as taking an anthropocentric or biocentric approach, concluding that the action patterns observed in the two campaigns more closely approximate the traditional anthropocentric approach according to which, alongside natural resources, the landscape and animals, human beings are (virtually) the only ones accorded a moral status.

During the 1990s, one of the longest environmental campaigns in Israel was waged against the construction of the Trans-Israel Highway (Highway 6). This campaign is examined in a study by Rabinowitz

\footnotetext{
${ }^{5}$ Hawken claims further that it is the largest social movement in history, the full scale of which remains unknown. Particularly interesting is the subtitle of Hawken's best-selling book Blessed Unrest: How the Largest Movement in the World Came into Being and Why No One Saw It Coming. It should be noted that the book is not a scientific study.
} 
(2002), who argues that the campaign's failure was a historic milestone, which showed that merely calling attention to damage to nature or the ecology is insufficient, and that one must also open up public discourse against developers to wider circles of influence on society, primarily the economy (Rabinowitz, 2002). ${ }^{6}$ One of Rabinowitz's central arguments is that conceiving the campaign's aims within the limited rubric of protecting flowers and fields misses the real value of the collective resource we refer to as the "environment." Thus, effectively, the campaign against the Trans-Israel Highway can be seen as an illustration of the difference noted above between ecological justice and environmental justice, and more broadly of the conceptual transition that some of the organizations have made from "ecological organizations" to "environmental organizations." Empirical evidence supporting Rabinowitz's argument can be found in an ethnographic study by Meislisch (2005), who meticulously documents the arguments and dynamics in the development of the campaign against the Trans-Israel Highway.

An important attempt at characterizing environmental campaigns in general has been made by De Shalit (2002), who comparatively examines a number of cases in Israel and the United States, citing 10 key reasons for environmental campaign's failure. The description of the cases and their analysis based on two models of environmental campaigns, the radical/populist model and the moderate/conventional model, show that extreme activism, unwillingness to compromise and alienation from the political system are normally a mistake. By contrast, taking political initiative, focusing on goals rather than organizations, and use of anthropocentric arguments are generally wiser and perceived more often as legitimate in terms of the enviro-political rules of the game.

Over the last decade, Israeli research on environmental campaigns and environmental organizations' place in Israeli society has expanded significantly. Amongst this literature, one can find concise and informative surveys of types of organizations and their organizational patterns (Binyamini, 2002), the role of environmental organizations in the planning system (Brachya, 2012; Hann, 2006), and their relative magnitude in civil society (Alon, 2007). More in-depth studies can be found on the political involvement of environmental organizations, in the context of distributional justice and environmental justice (Benstein, 2004), or their position regarding the Israeli West Bank Barrier (Sadeh, 2010). Other studies have offered in-depth accounts and characterizations of specific campaigns, such as the campaign to prevent wildflower picking (Furst, 2012), the campaign against hotel construction in the Sasgon Valley (Golan, 2010) and Palmachim Beach (Cassirer, 2012), as well as the legal campaign waged by Adam Teva V'Din against the Camp Ariel Sharon plan (also known as the Training Base City plan) in the Negev (Elad, 2009). The powerful impact environmental campaigns have had on environmental policy-making and the role of scientists in such campaigns is conveyed in a study by Gidron and Fischendler (2010), which focuses on the cases of the Michal settlement in Gilboa and the fish cages in Eilat. In addition, the present author conducted an ethnographic study on the activist organization Greenpeace Israel (Furst, 2008) as well as a cultural analysis of the effectiveness and significance of environmental organizations' activism (Furst, 2014). An up-to-date picture of the current structure and action patterns of environmental movement organizations in Israel can be found in a research report by Tal (2011).

In light of all of the above, the present article seeks to present a survey of the development of

\footnotetext{
${ }^{6}$ In his 2010 book, co-authored with Itai Vardi, Driving Forces: Trans-Israel Highway and the Privatization of Civil Infrastructures in Israel, Rabinowitz expands his argument, warning against the trend in planning exhibited in the case of Highway 6 of excessive developer privatization, which according to Rabinowitz, went as far as allowing national transportation policy to be dictated by a private corporation, Derekh Eretz (Rabinowitz \& Vardi, 2010).
} 
environmental movement organizations in Israel from the establishment of the State of Israel through the progress made over the last two decades (The Sustainability Period, below). The aim is to paint a portrait of the environmental movement in Israel in general and the development of action patterns of environmental campaigns in particular. Hence, the survey focuses on activism by organizations in high-profile campaigns in which they took part while highlighting their impact on the following issues: mobilizing activists and resources, forming and implementing a vision, negotiating, and gaining recognition among decision-makers and the public. The account relates to activism exclusively on the national level, while noting collaborations with local and international organizations, and is divided into three periods corresponding to the stages development of the planning and environmental establishment in Israel: establishment, institutionalization, and sustainability. ${ }^{7}$

\section{The Establishment Period (1948-1963)}

Central to this period was the Sharon Plan, in effect the first professional planning document drawn up after the establishment of the State. The architect Arieh Sharon, who headed the Planning Department of the Prime Minister's Office, drafted a national plan, which defined building areas, "green lines," and even six large "parks," the only consideration in their determination being their alleged "historical sacredness," "biblical legacy" or archaeological significance. ${ }^{8}$ The plan was officially published in 1951, under the title "Physical Planning for Israel." Azaria Alon writes of the manner in which the six parks were incorporated into the plan.

The planners themselves actually knew virtually nothing about the country. The Negev and the Galilee were as familiar to them as the moon. They drafted the park plan based on suggestions made by Amot Zehavi and myself. They paid us no mind; we were just pushy... ${ }^{9}$

In the same year in which the Sharon Plan was made public, the Committee for Nature Preservation was established, the initial seed from which within two years the Society for Protection of Natureemerged. ${ }^{10}$ The most influential (and likely the first and last) of the Committee's campaigns was aimed at saving the oak forests in the hills of the western Lower Galilee (today Kiryat Tivon). This was effectively the first public environmental campaign in Israel, and it is interesting to discern in it a political-cultural tone suggesting the value of personal sacrifice, and even political tension between Jews and Arabs, all in an environmental context. The following statement was made in an argument presented by members of the Committee for Nature Preservation, who had joined forces with members of Kibbutz Alonim.

We sacrificed [in the past] forces and blood to prevent the annihilation of the ancient oak trees by our Arab neighbors, so there can be no justification for the oaks now being uprooted by the State of Israel. ${ }^{11}$

This campaign bore fruit, as the director of the JNF, Yosef Weitz, was persuaded and ordered that the new homes in Tivon be constructed without damaging the ancient trees. The Committee for Nature Preservation continued holding scientific conferences, but had only a minor public impact. The change came with a chance

\footnotetext{
${ }^{7}$ For more on these periods as mirrored in the planning establishment, see Feitelson, 2010.

8 The six parks were: the Carmel, the Judean Hills, Mount Meron, Nahal Poleg, Caesarea and Hamakhtesh Hakatan (The Small Crater). Regarding the latter, Ben Gurion once gave the instruction (never realized) to close the Crater and introduce lions into it so that it would become a biblical zoological gardens.

${ }^{9}$ Regev, 1993.

10 The Committee for Nature Preservation was organized upon the initiative of the zoologist Professor Heinrich Mendelssohn, who started identifying threats to the Israeli landscape and natural monuments. The Committee dealt mainly with scientific research topics and attempts to influence the establishment, without popular educational activity. Other members of the Committer included Yaacov Galil, Dvorah Ayalon-Sereni, Rachel Gavrieli, Alexander Barash, Yaacov Hoofien and Haim Merom.

11 Regev, 1993.
} 
encounter between Amotz Zehavi, a zoology student, and Azaria Alon, a nature teacher, two nature lovers, who decided to protest against the state's plans to drain the Hula wetlands. During their campaign, which though did not prevent the drainage of the Hula Valley, resonated powerfully among the public at the time, the two sensed that genuine change could only be effected through the general public. Hence, they founded a new body: Ayala - the Israeli Association for Nature Preservation, which was legally registered as a voluntary association in 1953 under the name The Society for the Protection of Nature in Israel (SPNI). ${ }^{12}$

In the years that followed, the SPNI engaged in public educational activism, which included leading nature hikes, organizing scientific conferences for scholars and the general public, establishing a field school, and publishing periodicals and nature books. The SPNI's impact on the establishment at the time was minor, and generally speaking, its activism could be described as being of a very moderate character. Its discourse centered on nature and ecology exclusively, while the term "environment" (or "quality of the environment" [eichut hasviva]) was not deployed at all. In effect, the SPNI did not lead even a single environmental campaign during the establishment era, and most of its activity focused on education and information. Attesting to such is the small number of campaigns waged during this period, which were led by individual actors who devoted themselves to a given cause: the failed Hula Valley campaign, and two very successful campaigns, one against gravel mining on the shores of the Western Galilee and the other against the plan for diverting the water from the Dan River.

However, the main cause taken up by the SPNI during this era was creating a government body that would be responsible for nature protection. Thus, owing to public pressure on the government that grew out of the failed Hula Lake campaign, in 1963, with support coming mainly from the Ministry of Agriculture, the Nature Reserves Authority and the National Parks Authority were established. The Planning and Building Law, legislated shortly thereafter, in 1965, completed the formal national planning layout, notwithstanding the fact that nature preservation and the environment were minor features of the law. ${ }^{13}$ The "public relations" aspect of the activity henceforth took on the character of a "division of labor" between the existing organization, which had already gained significant public recognition given the popular nature of its activism (SPNI) and the new government bodies, which were accorded legal authority to plan, establish and manage nature reserves, national parks and natural monuments. The shared values and positive interaction between these bodies, which derived their legitimacy and moral justification for their activities from broad-based public support, led to the first truly successful nature preservation campaign in Israel - the campaign to prevent wildflower picking. This establishing event served as a harmonious example of a campaign that brought about significant cultural change, and gave rise to a new environmental code of ethics, which defined relations between people and the environment in Israel. ${ }^{14}$

The (only) other environmental organization of the establishment period was the Council for the Prevention of Air Pollution in Israel (MALRAZ), which was established on the initiative of a group of citizens from Tel Aviv and Haifa. ${ }^{15}$ The reason for the Council's establishment was to serve as a body that would oversee the implementation of the Prevention of Nuisances Law (known as the Kanovitz Law, 1961), which

\footnotetext{
12 Regev, 1993; Tal, 2006; Alon, 2012.

13 For a detailed survey of the process of establishing these government bodies, see Katz, 2004.

${ }^{14}$ For a detailed account of the organizations' activity in the campaign and its significance, see Furst, 2012.

15 The Council was headed by GenyaKanovitz (widow of MK Shimon Kanovitz, who initiated the Prevention of Nuisances Law of 1961), Antonio Pranio, an engineer who specialized in air pollution, and YedidaBeeri, a very environmentally conscious attorney.
} 
addressed air and noise pollution. MALRAZ had a new and unique status, as it was headed by public officials (the most prominent of them being Supreme Court Justice Zvi Berenson and Deputy Mayor of Tel Aviv Simha Erlich), its activists were volunteers from the general public and academia, and its financial support came from the establishment (the Ministry of the Interior and the local authorities). Regarding the nature of the Council's public activism, we can learn a great deal from the following excerpt from a newspaper article.

The Council will deploy volunteers who will write down the license plate numbers of cars emitting exhaust smoke, and other details, on postcards. The Council will then convey the details of the cars "prone to" exhaust smoke emission to the Licensing Office, which will in turn summon the drivers to have their cars checked and ask that they repair the defects. Many of the volunteers who have already begun this work have claimed it would be difficult to fulfill their duties, as almost all diesel cars emit exhaust smoke, even if the state of trucks as far as emissions are concerned is more satisfactory that the state of buses and cars. The Council seeks more volunteers to identify foci of pollution and asks them to contact the Council at the following address: POB 1500, Jerusalem. The Council will also hold seminars for drivers where they will be taught methods of maintaining car engines in order to prevent exhaust smoke emission. ${ }^{16}$

According to Tal (2006), MALRAZ's activity was not very effective in its initial years, as the vision that crystallized was insufficiently focused and public enlistment was not pronounced. MALRAZ's new message on environmental issues (which were not yet termed as such semantically) and the organizational character of the Council, as a public body collaborating with citizens, were apparently ahead of their time. It is possible that in order to generate significant activism, an identity-building campaign was needed, and this was just around the bend (the campaign against the Reading Power Plant, below).

\section{The Institutionalization Period (1964-1989)}

The legislation passed in the mid-1960s mentioned above served as an important turning point in the organizational development of the environmental movement in Israel, as the nature preservation and planning and building laws created for the first time a formal operational framework into which the few organizations existing at the time entered. Furthermore, the new legislative framework granted henceforth professional and public legitimacy to the organizations' activity, which created a link between the development process and the interest of nature preservation.

A generation spanned the beginning of the institutionalization period and the transition to the sustainability period that followed. During those 25 years, the ideas of the first two public environmental organizations (SPNI and MALRAZ) penetrated the public and political consciousness, and this was manifested in the establishment of a few more organizations and the intensification of their activism. This era could be viewed as an interim period, as it fell between the establishment phase and the sustainability phase, in which the environmental movement reached its climax. During the institutional period relations between environmental organizations and the establishment strengthened, but they had yet to gain full cultural recognition among the public or among decision-makers at the national and local political level. Environmental organizations' transition from the biocentric approach (centralizing nature) to the anthropocentric approach (centralizing the human being) was not accompanied by a practical vision that could have had an impact on decision-makers and Israeli society, which still viewed environmental organizations as romantic and naïve

\footnotetext{
16 "Preparations for Implementation of the Kanovitz Law for the Prevention of Air Pollution," Haaretz, 22.10.1962. No author indicated.
} 
nature preservationists. Yet, the sundry challenges of development in the planning and economic system, as well as the expansion of building activity in the West Bank and Galilee following the Six Day War, led environmental organizations to a different way of thinking, which translated into more proactive and focused activism.

The number of environmental campaigns during this period was actually relatively small. The majority of the broad-based campaigns dealt with issues related to national infrastructures, such as the establishment of power plants (Reading, Hadera), mining activity (Mount Carmel and Mount Zin) and the installation of communications facilities (the "Voice of America" station). Local or limited campaigns led by grassroots organizations were virtually non-existent during the institutionalization period (a few exceptions were local campaigns against the construction of the Tefen-Carmiel highway and against the establishment of a new settlement in the Um al-Safa forest on the West Bank, which combined for the first time local and national activism led by the SPNI). It is possible that the relatively minor activity evidenced by environmental groups during this period is related to the emergence of a new major player, the Israel Environmental Protection Service (EPS), which was established in 1973 as a small department within the Prime Minister's Office. The Service functioned as an address within the government that provided a professional response on environmental issues, and its cooperation with the few existing environmental bodies of the era and as well as academia ${ }^{17}$ ostensibly met the needs of the time.

As for the campaign's effectiveness, it may well have reached its peak during the institutionalization period, as most of the goals the environmental organizations set for themselves were achieved. Among these, the following cases are noteworthy: the setting of a legal precedent in the campaign against the Reading power plant in Tel Aviv (mandatory air pollution monitoring), the cancellation of the Carmel mine plan and the declaration of the area as a national park, the selection of an alternative (environmentally preferable) site for the proposed Hadera power plant in the Sharon, and the nullification of plans to establish a new settlement in the Um al-Safa forest, as well as the Voice of America relay station scheme in the Arava. However, it seems that the main impact the SPNI and MALRAZ, which continued to be dominant bodies during this period, had was instilling new environmental protection values (and not merely "nature values"), leading a significant cultural transformation (the wildflower and Reading power plant cases) and setting new planning standards (mandatory landscape inspection in road construction plans, in the case of the Tefen-Carmiel highway). Even if not explicitly stated at the time, during the institutionalization period, early signs of sustainability values began to emerge, including public involvement, institutional transparency, public responsibility, emphasis on the scientific aspects of the environment, and the relationship between environmental justice and social justice.

An important reference point during this era was the establishment of Life and Environment (Hayim V'Sviva)-The Israeli Union of Environmental NGOs as an umbrella organization for all the environmental non-governmental organizations in Israel. Established in 1975 through the initiative of MK Yosef Tamir (Liberal Party/Likud) and with the cooperation of Azaria Alon (general secretary of the SPNI) and Avraham Yafeh (chairman of the Nature Reserves Authority), ${ }^{18}$ the organization was the outcome of Tamir's

\footnotetext{
${ }^{17}$ An important contribution to the relationship between the academic and scientific community and the emerging environmental field was made by the Israeli National Committee on Biosphere and Environment (VIBAS), which was established in 1970 under the auspices of the National Council for Research and Development.

18 Goldstein, 2002.
} 
participation as a Knesset representative in the first UN conference on the environment held in Stockholm in 1972. Tamir was strongly moved by the ideas raised at this conference and asked that Israel be included in the global umbrella environmental organization established under the conference's auspices as part of the UNEP. With the establishment of Life and Environment, a number of public organizations whose primary endeavors were not environmental per se (among them, the Israeli Housing Culture Association, BnaiBrith, Na'amat and Rotary), as well as a number of professional associations (including the Association of Engineers in Israel and the Israeli Society of Ecology and Environmental Sciences), joined Tamir. Life and Environment's main success was in adapting a universal formulation of the environmental idea to the Israeli context by infusing it with a legal, political and governmental substance, which began to take root among the public. Environmental campaigns henceforth became a multidimensional issue, which incorporated cultural, scientific and political thinking. Yet, most of the public activism during this period continued to be done by the environmental organizations themselves (mainly the SPNI and MALRAZ), while Life and Environment comprised a conceptual framework for international cooperation, initiating laws and representation in the planning institutions. $^{19}$

The image of the environmental movement in Israel at the end of the 1980s is one of a mere handful of activist organizations (approximately ten out of the twenty that existed at the $\operatorname{time}^{20}$ ) that acted against infrastructural plans that were clearly destructive to natural assets, the environment and wildernesses and profound environmental threats (air pollution, noise pollution, radiation). While the institutionalization of government organizations dealing with environment may have allowed for an effective dialogue between themselves and environmental organizations, still absent during this period was a major breakthrough in terms of penetrating the public consciousness, a change that only occurred at the beginning of the 1990s with the waves of immigration from the former Soviet Union and Ethiopia, which made for the biggest planning challenge the country faced since the establishment of the State. The extensive activity of environmental organizations during this period will now be examined at length.

\section{The Sustainability Period (1990 Through the Present)}

As indicated above, the background of the period includes the large waves of immigration from the former Soviet Union and Ethiopia in the early 1990s, which posed a major challenge planning-wise as well as socially and politically, and also led to unprecedented activism on the part of environmental organizations in Israel. This shift is evidenced by the fact ${ }^{21}$ that in 1990 the number of member organizations in Life and Environment was less than twenty-five, and of them only a few that actually dealt with environmental issues as their primary pursuit, while today (2012), more than 100 organizations of an unquestionably environmental character are listed under the umbrella organization, approximately half of which were founded in the last decade

\footnotetext{
${ }^{19}$ By virtue of an amendment to the Planning and Building Law (1965) initiated by Tamir, Life and Environment representatives were accorded the status of representing the public on environmental issues in the National Council for Planning and Construction (Goldstein, 2002). One of the more novel initiatives at the time, which failed to be realized, was Tamir's attempt to include in the part platforms and local elections plans dealing with environmental issues. From: "Proposing to Include Environmental Plans in Elections," Maariv, 20.12.1976 (no author indicated). It should be noted further that Tamir also spearheaded the establishment of The Council for a Beautiful Israel (1968), which while it did not engage in activism and waging environmental campaigns in the usual sense, was a pioneer in creating the cognitive link between the environment and the community at the local level.

${ }^{20}$ Statistics according to the Israeli Center for Third Sector Research, Ben Gurion University of the Negev. See Binyamini \& Pizmony-Levy, 2002).

${ }^{21}$ Ibid., See also: Tal, 2011.
} 
(2000-2010). A quantitative assessment of these organizations shows the following: ${ }^{22}$

More than $80 \%$ of the organizations are registered as non-profits or voluntary associations.

The number of organizations addressing national issues is double that of those addressing local ones.

A majority (55\%) of the organizations were established out of a desire for broad-based activism and promotion of a collective idea, while only $45 \%$ were formed to pursue specific objectives. What they had in common was the manner in which they were established, which was always the result of personal initiative by individuals or small groups.

Over half the organizations in Israel have small memberships (less than 50 ), while a tiny minority (7\%) have 5,000 members or more.

In most of the organizations, the causes taken up are diverse (environmental planning, wilderness preservation, public health, nature preservation and biological diversity, sustainability, environmental justice, public involvement, air quality, hazardous materials), but there are some important issues that are hardly addressed at all in the organization's platforms, the most notable among them being population growth, desertification, land erosion and fair trade.

The dramatic quantitative increase in the number of organizations that occurred in the early 1990s attests to conceptual and political transformations that stemmed from both internal/domestic factors (the foremost among them being the immigration challenge) and external/international ones (increasing environmental consciousness globally), but were also the product of the public educational activism that had gained momentum in previous decades.

Firstly, there was a turn toward specialization and professionalization. The increasing prominence of environmental issues in the public consciousness spurred individual experts and groups of experts to form niche organizations focusing on specific issues (Adam TevaV'D in as a legal clinic, Transport Today and Tomorrow on issues related to transport infrastructures, Zalul on protection of Israel's seas and rivers), or a spatial aspect-both on a local level (Shomra in the Jerusalem Hills, TAHLES - Carmiel Residents for the Environment in Carmiel) and an international level (Greenpeace Israel, Friends of the Earth-Middle East). Part of the background to this professionalization of organizations was the drafting of National Outline Plan 31, which created a new planning language that placed greater emphasis on environmental issues, primarily the new concept of "open spaces" or wildernesses. The legal framework of the drafting and ratification of NOP 31 could be said to be identical to the legislative processes of the mid-1960s mentioned above, as both comprised an effective framework of action for the organizations, a source of legitimization from the public's perspective and a means through which organizational and ideological identity formation was realized.

One indication of this professionalization and development of environmental specializations can be observed in the activity of the SPNI, which during this period became a sort of organizational conglomerate, which incorporated many different sub-bodies specializing in a range of issues ${ }^{23}$ the foremost of which was

\footnotetext{
22 Statistics from Tal, 2011.

23 Thus, for instance, in 1992, the Open Landscape Institute (OLI), which engages in empirical research on planning and "open landscapes," was established in the framework of the SPNI. The educational activities of the SPNI were then transferred to field schools and scouting clubs, while its nature protection and consciousness raising activities on these issues henceforth took place in urban centers ("communities") and special ecological centers (The Center for the Study of Bird Migration at Latrun, the Jerusalem Bird Observatory). To these can be added the trail marking project started in the 1950s by Uri Dvir, and the Society for Preservation of Israel Heritage Sites, founded in 1984 by the SPNI (the Society became an independent body in 2008). In the past, there was even an overseas travel department, but at the end of the $1990 \mathrm{~s}$, this was converted into an independent business corporation, Roim Olam.
} 
environmental planning, which, by virtue of NOP 31, began crystallizing as a relevant and significant professional field within the planning institutions. Meanwhile, the SPNI and the Nature Reserves Authority became parties to the planning process almost from its outset, their activity focusing on having a meaningful impact on this process. These trends precipitated a transformation of the identity and character of the organizations, which henceforth were no longer spear headers of campaigns, but rather actors mediating between the public and the establishment in the ongoing planning process.

Secondly, apparent was an increasing trend of alliance and coalition-building, some long-term (the Coalition for the Preservation of the Jerusalem Hills, Sustainable Negev) and some more targeted (the Movement to Stop the Trans-Israel Highway and the Forum for Responsible Planning, which opposes the reform to the Planning and Building Law). A third aspect of the organizations' activism over the last two decades is obviously related to the growing number of grassroots organizations, which have an unmistakably cultural component, such as the activists' identity (Haredim for the Environment in the Haredi community, Green Course and Green Action as student organizations) or spiritual orientation (the Heschel Sustainability Center for Environmental Learning and Leadership, Hebrew Nature (Teva Ivri), which seeks to establish a link between environmental and Jewish traditional values, and Eco-cinema, which promotes environmentally-minded film making).

It is evident that these three trends - professionalization, collaboration and identity formation, attest to the creation of a diverse culture within the environmental movement, which in most cases translates into political power manifested in two complementary transformational processes: on the one hand, an increasing capacity to enlist public support and recognition by the establishment, and on the other hand, a waning of the antiquated image of environmental organizations as intransigent opponents of virtually every form of development or as headstrong romantics out of touch with present needs. It is important to note that in the background of these processes were two external events that significantly impacted the empowerment of environmental organizations and the public and political response to their messages, which swung from dismissal to recognition: the Maccabiah bridge collapse (1997) and the Shayetet 13 Kishon River affair (2000-2002). These two cases in which environmental organization were not directly involved, and which could hardly be defined as typical public environmental campaigns, had an unprecedented resonance among the public, mainly due to the catastrophic outcomes (death and cancer) evidenced in them of ongoing environmental pollution in the rivers. These cases served as a kind of "proof" and tragic illustration of the arguments made by environmental organizations regarding the need for environmental protection.

These trends find expression in the character of the campaigns waged in Israel since 1990, as they span almost every area of social and political action (whether narrowly "ecological" or broadly "environmental"). Either way, these campaigns continue in most cases for many years, in accordance with the scope of the plans and the economic power backing them (for instance the Safdie Plan or natural gas drilling in the Mediterranean). Another salient trend that emerges from a survey of the campaigns during this era is the increasing legal-planning character of the campaigns (the most prominent examples of which are the Coastal Protection Law of 2004 and the reforms to the Planning and Building Law since 2010).

An attempt to assess the impact (effectiveness) of environmental organizations' activism over the last two decades can be done in a number of ways: on a narrow level, one could examine how many campaigns fully achieved their stated aims (as in the fish cages, Safdie Plan and Michal settlement cases, in which the plans 
were scrapped entirely), how many partially or temporarily achieved them (as in Karkur Hills (Nes Ziona) and Palmachim Beach cases, in which nullification of the plans had no legal or financial anchoring) and how many failed (as in the Trans-Israel Highway and Nahal Yitlah railway tunnel cases). However, on a broader, qualitative level, one could view the campaigns that ostensibly failed as bringing about a certain change that was in fact assimilated and having a discernable impact on the planning establishment and/or the public. The cases of the three major environmental campaigns of the 1990s-Highway 6, the new Ben Gurion terminal, the Dodaim waste sites in the Negev-are clear examples of such. In these instances, the organizations did not succeed in stopping the plans, but their campaigns and the dialogue they engaged in with the establishment effected a cultural change manifested in a vast number of regulatory, ethical and even technological innovations. ${ }^{24}$ An important practical expression of this cultural transformation was the anchoring of the representation of environmental organizations on the district planning and government commissions in law, which occurred with the passage of the Representation of Environmental Public Bodies Law in 2002. It is possible, then, that seemingly unsuccessful environmental campaigns have the potential to generate other marginal benefits, which the campaigns' spear headers may not have intended.

\section{Discussion}

A schematic portrait of the structure and development of the environmental movement in Israel as related above can be drawn on the basis of the palimpsest model ${ }^{25}$ used by Doyle and Kellow (1995) to describe the environmental movement in Australia. According to this model, the environmental movement is the sum of actions taken by individual persons (local activists) who join specific action networks at the local level, and who with time and as a result of common interests unite to form organizations. Over time, and due to various conditions and needs (mainly social and political), these organizations undergo institutionalization and after a significant period, sometimes many years, become stable organizations. As environmental conflicts intensify and become multidimensional and unquestionably political (such as the campaigns against the Safdie Plan or the reforms to the Building and Planning Law), the organizations form ideological alliances to advance their common goals or to justify their existence and their cultural identity, such that, at a certain point in time, one can look at all the components of this activism and define them as a cohesive social movement with a common cultural identity, based upon sustainability values and diverse behavioral norms. The process by which the SPNI was established and institutionalized can serve as a concrete example of this evolution, beginning with the stage of the idea of activists joining forces, through institutionalization and culminating with its transformation into a fundamental part of the overall movement. On the other hand, there is another model, of establishing an organization that is institutional from its very outset, with no preliminary stages, such as in the case of Adam TevaV'din. Figure 2 presents the above in schematic form.

\footnotetext{
24 These changes and innovations included: upgrading the engineering standards for highway construction (Highway 6), setting strict environmental standards (Ben Gurion terminal), public involvement and compensation (Ben Gurion termianl) and generating a public discourse that bound together environmental justice and social justice (Dodaim, Highway 6).

${ }_{25}$ A palimpsest (from the ancient Greek palimpsestos, "scratched again", is "a manuscript page, either from a scroll or a book, from which the text has been either scraped or washed off so that the page can be reused, for another document" (Wikipedia). Figuratively, the term today is used to describe a multidimensional or multilayered situation or text, in which the new incorporates the prior.
} 


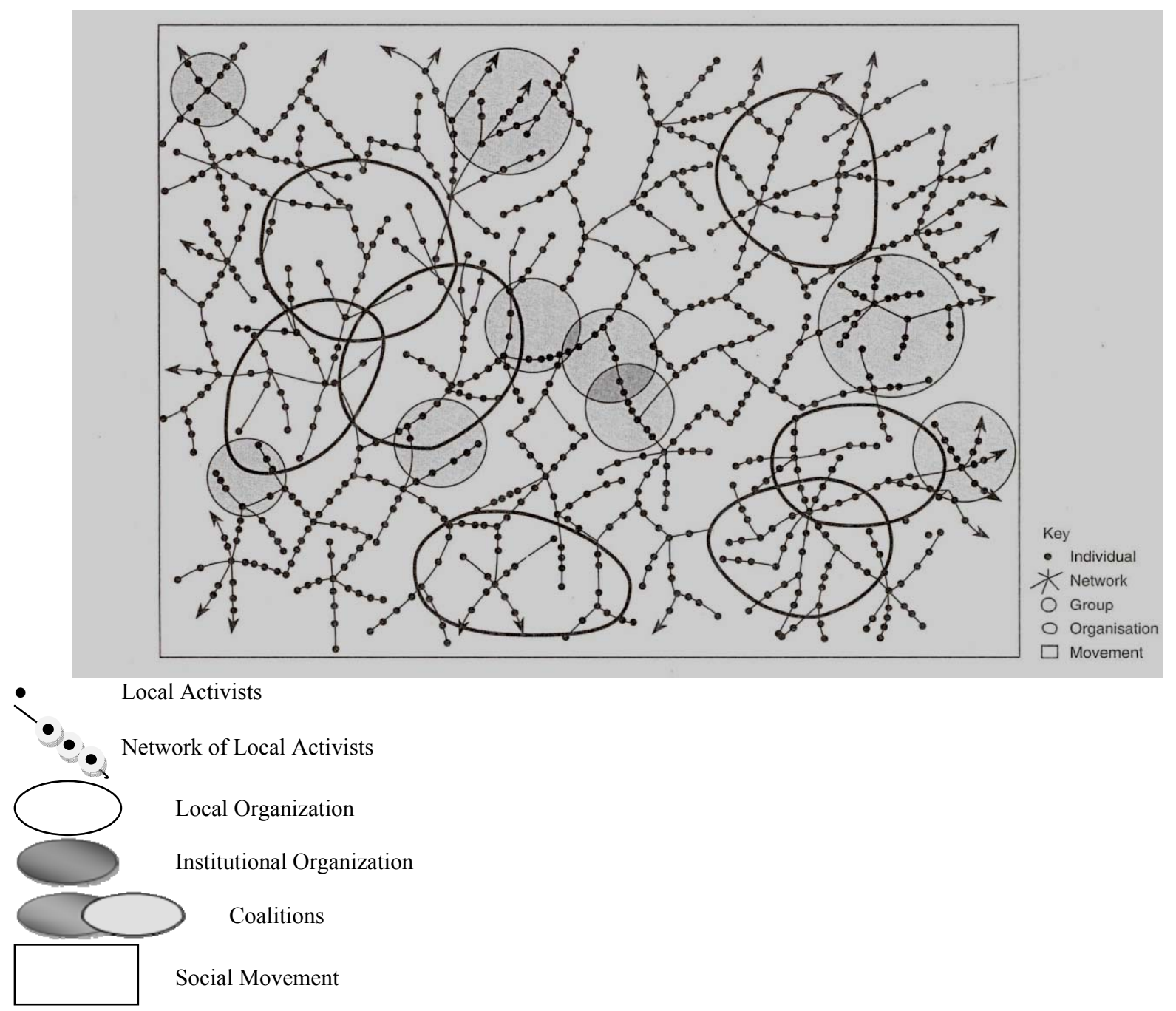

Figure 2. Palimpsest model-Structure and development of the environmental movement in Israel.

The nature of environmental activism in Israel, as reflected in this general survey, is diverse, although clearly evident is a tendency toward intra-establishment action and away from automatic opposition to all development. The three phases described above represent a dialectical process undergone by the environmental movement in Israel: from a naïve romantic approach that centralizes nature (the establishment phase) to an opposite approach (the institutionalization phase), which is scientific-technological in nature, and centralizes human needs and quality of life (the anthropocentric approach of "environmentalism"). The third phase, marked by the emergence and implementation of sustainability values comprises an integration of the two approaches above, by centralizing the community and locality, and through a new environmental ethical outlook on the environment as defining personal and collective identity and not merely providing material resources for living. Regarding the character of their messages and their ideological outlook, the environmental movement in Israel seems to be involved in a vast range of areas, both narrow and broad, with a tendency among the older national organizations to deal with national infrastructural issues or local issues of particular significance (the fish cages, the Michal settlement), versus a tendency amongst local organizations to focus on NIMBY ("not in my back yard") campaigns. 
This trend amongst local organizations is open to bivalent interpretation: as a tendency toward a selfish concern with issues in one's immediate environment exclusively, or rather, as a tendency toward caring and a desire to authentically improve one's quality of life. We are talking about two different interpretations subject to judgment in the eye of the beholder. Generally speaking, and in view of another study by the present author that analyzed political cultures of environmental organizations, ${ }^{26}$ a number of insights can be made regarding the character and image of the environmental movement in Israel.

Amongst the Israeli public, there is a very high level of distrust of the establishment in virtually all its departments, branches, forms and manifestations. This fact empowers environmental organizations, which serve as a most credible alternative, mainly because they are viewed as being free of outside interests and as promoting a higher cause that is predominantly within the general consensus.

The impact environmental organizations' public activism has on campaign outcomes or the conflict is palpable, but is not the only factor, and sometimes not even the critical factor determining conflict outcomes. In many cases one can point to external factors that affected the course of a given campaign and its outcomes, for instance in the case of the antenna at Tzoran (financial and technological factors leading to the site's closure) or the campaign against wild flower picking (organizational factors of identity building, seeking for legitimization).

It is hard to devise a clear formula for an environmental campaign's success, but it seems that the right combination of the three elements enhances the likelihood of achieving greater effectiveness: raising an emotional object as the campaign "flag" (flowers, coral, nature reserves); rationally articulating the campaign's key message (presenting well-supported alternatives or discrediting the raison d'être of proposed plans); proactive and persistent leadership.

The general structure of the environmental movement in Israel can be depicted as three concentric circles representing the three main types of organization: the inner circle being the environmental establishment, including the Ministry of Environmental Protection in all its various branches ${ }^{27}$; the outer circle including a small number of core NGOs of a unique professional character, which operate on a national level ${ }^{28}$; and the expanding circle representing dozens of local grassroots organizations, some of which are ad hoc and dissolve at the end of a given campaign.

\section{Conclusion}

We have seen that the history of environmental activism in Israel can be divided into three periods, which correspond to the development of the country's planning and environmental establishment: firstly, the establishment period, whose milestones included the Sharon Plan, the establishment of the SPNI and MALRAZ, and the enactment of the Kanowitz Law and the National Parks and Nature Reserves Law (1963). The phase of

\footnotetext{
${ }^{26}$ See Furst, B. Political Cultures in Environmental Organizations in Israel: Characterization, Effectiveness and Significance. Doctoral Thesis in Philosophy, the Hebrew University of Jerusalem. See also: Furst, 2013.

27 Specifically, the Israel Nature and Parks Authority, the National Parks, Nature Reserves and National Sites Council, the environmental units of the ministry, the river authorities and two government companies (the Environmental Services Company and the Ariel Sharon Park Company).

28 This circle includes Life and Environment as an umbrella organization, the SPNI as a planning and educational body, Adam Teva V'Din as a legal warrior, the Heschel Center as promoting environmental learning and leadership, and Green Course and Greenpeace as radical activist organizations. It should be noted that regarding the JNF, there is a problem of identity, given its special status as a powerful establishment body spearheading development while also being an organization that regards itself as contributing to environmental preservation.
} 
institutionalization that followed was marked by the establishment of government bodies with specific missions - the Nature Reserves Authority, the National Parks Authority, the Environmental Protection Service, and their integration into the national planning system. The institutionalization period concluded with the establishment of the Ministry of the Environment (1989), and the transition to the third period, sustainability. Notable during this phase was a trend toward multidimensional planning policy spanning many different spheres and including broad regulation. As far as the environmental organizations are concerned, the three periods served as a cultural framework of action in which they emerged, acted and shaped environmental discourse and practice in Israel. An indication of the profound effectiveness of environmental organizations, and of the public recognition of the importance of the ethical transformation they were leading can be found in the following words, which were part of a 2001 Supreme Court ruling.

Consciousness in Israeli society regarding the environment and preservation of natural assets for all and for subsequent generations is still undeveloped. We are sorely lagging behind other developed countries on environmental issues. This is particularly grievous given the very limited nature areas in Israel, such that any wrong decision could be a fatal and irreversible blow to the assets that we are obliged to vigilantly protect... We should praise the fact that private organizations have taken this important mission upon themselves, in addition to government planning bodies. We should support them in their efforts to protect a charming corner in nature... [there is] a need to fortify and encourage the various bodies keeping the faith regarding environmental preservation. $^{29}$

\section{References}

Alon, Y. (2007). Environmental organizations. Alon-Israeli Center for Third Sector Research, Vol. 25, A-B. [In Hebrew]

Alon, A. (2012). Nature and man. Tel Aviv: Am Oved. [In Hebrew]

Bar-Dor, S., \& Tal, A. (1996). Promoting public activism for the environment in Israel. Report Submitted to the Karev Fund, Tel Aviv. [In Hebrew]

Brachya, V. (2012). Environmental planning in Israel: The development of environmental thinking in planning processes in Israel. In S. Hasson (Ed.), Shaping space in Israel. Jerusalem: Keter. [In Hebrew]

Benstein, G. (2004). Place and the other-The place of the other: Narratives and the environment between consensus and conflict among Jews and Palestinians in Israel (Doctoral dissertation, The Hebrew University of Jerusalem). [In Hebrew]

Binyamini, S., \& Pizmony-Levy. (2002). Environmental organizations in Israel-A movement in movement. In Signs of Life 2002. Tel Aviv: Babel Press. [In Hebrew]

Binyamini, S. (2002). Trends in the Environmental Movement in Israel-Expanding the environmental message. In Signs of Life 2002. Tel Aviv: Babel Press. [In Hebrew]

Cassirer, S. (2012). The Palmahim Beach campaign: Media representations and organizational aspects of a public environmental campaign (Master's thesis, Tel Aviv University). [In Hebrew]

Castells, M. (1997). The power of identity. Oxford, UK: Blackwell Publishers.

De Shalit, E. (2002). The ten commandments for complete failure in an ecological campaign. Panim, 21, 12-21. [In Hebrew]

Doyle, T., \& Kellow, A. (1995). Environmental politics and policy making in Australia. South Melbourne, AU: Macmillan.

Elad, N. (2009). The establishment of training base city in the Negev as leverage for environmental regulation of Ramat Hovav contaminants. In A. Oren (Ed.), Space of security: A new approach to the use of land resources for military and security purposes in Israel. Jerusalem: Van Leer Institute. [In Hebrew]

Feitelson, A. (2010). Proactive planning, regulative planning, sustainable development and everything in between. In A. Razin (Ed.), National, regional and metropolitan planning in Israel. Jerusalem: Floerheimer Studies. [In Hebrew]

\footnotetext{
29 Justices Aharon Barak, Izhak Englard and Ayala Procaccia, July 2001, in a Supreme Court ruling on an appeal by Adam, TevaV'Din against the verdict of the Haifa District Court (Civil Appeal 8116/99). The case dealt with the establishment of a petrol station near Givat Ada, in an areadesignated in National Outline Plan 31 as an "open rural landscape zone".
} 
Furst, B. (2008). Local action-Global thinking: On the nature of an environmental protest organization's campaign-An illustration of greenpeace Israel. Politics, 18, 27-55. [In Hebrew]

Furst, B. (2012). Morphology of cultural change: The campaign to save the wildflowers as an influential factor in the shaping of space. Horizons in Geography, 78, 26-47. [In Hebrew]

Furst, B. (2014). Environmental campaigns in Israel and their spatial impacts. In L. Leonard and S. Kedzior (Eds.), Occupy the earth: Global environmental movements. UK: Emerald Books.

Gidron, Z., \& Fischendler, A. (2010). Science, policy and uncertainty: The role of the sciences in environmental policy in Israel. Jerusalem: Floersheimer Institute, The Hebrew University of Jerusalem. [In Hebrew]

Gottleib, D. (2004). Modes of activism and impact of extra-governmental environmental organizations (The society for the protection of nature in Israel and Adam Teva V'Din) on coastal planning 1997-2003 (Master's thesis, Haifa University). [In Hebrew]

Goldstein, Y. (2002). Betrayal of the chosen land: The socio-environmental threat. Jerusalem: Keter. [In Hebrew]

Golan, Y. (2010). Last call for the Sasgon Valley. Kibuttz Samar: Dahfor Press. [In Hebrew]

Hacohen, E. (1978). Love of the flowers of Israel. Teva V'Aretz, 20(2). January-February. [In Hebrew]

Hann, I. (2006). Environmental organizations and the planning system. Mivnim, 261, 36-38. [In Hebrew]

Hasson, S. (2009). Environmental ethics and politics. In A. Kasher (Ed.), Mevuot Le'etika (1). Jerusalem: Magnes Press. [In Hebrew]

Hawken, P. (2007). Blessed unrest: How the largest movement in the world came into being and why no one saw it coming. London, UK: Penguin Books.

Karassin, O. (2001). Organizations acting for quality of the environment and life in Israel. National priorities in the environmental field in Israel: Position document 2. Haifa, Israel: Samuel Neaman Institute for Advanced Studies in Science and Technology. [In Hebrew]

Katz, Y. (2004). Stopping the bulldozer. Ramat Gan: Bar Ilan University.

Meislisch, M. (2005). The campaign against the trans-Israel highway: Documentation of an environmental campaign. Jerusalem: The Jerusalem Institute for Israel Studies.

Paz, U. (2010). Till it and tend to it-Nature protection in Israel. Jerusalem: Ariel. [In Hebrew]

Rabinowitz, D. (2002). Real estate yielding highway. Panim, 21, 23-31. [In Hebrew]

Rabinowitz, D., \& Vardi, I. (2010). Driving forces: Trans-Israel highway and the privatization of civil infrastructures in Israel. Jerusalem: Van Leer Institute and Kibbutz Meuhad. [In Hebrew]

Regev, O. (1994). Forty years flourishing: The society for the protection of nature in Israel 1953-1993. Tel Aviv: The Society for the Protection of Nature in Israel. [In Hebrew]

Rootes, C. (1999). Environmental movements: Local, national and global. London, UK, Portland, OR: Frank Cass.

Rootes, C. (2003). Environmental protest in Western Europe. Oxford, UK: Oxford University Press.

Sadeh, S. (2010). Evergreen: Environmental organizations and the West Bank barrier project. Theory and Criticism, 37, $184-211$. [In Hebrew]

Shperman, K. (2007). Environmentalism: Caring for the environment, nature preservation and the ecological fabric. Parliament (Online Publication), (Vol. 55). Jerusalem: Israel Democracy Institute. [In Hebrew]

Snow, D., Soule, S., \& Kriesi, H. (2004). Mapping the terrain. In D. Snow, S. Soule, and H. Kriesi (Eds.), The blackwell companion to social movements. Oxford: Blackwell Publishing.

Tal, A. (1994). The environmental movement in Israel: Trends, needs and potential. Research Report Submitted to the JMG Fund, Ben Gurion University of the Negev. [In Hebrew]

Tal, A. (2002). Pollution in a promised land. Berkeley, CA: University of California Press.

Tal, A. (2006). The environment in Israel. Tel Aviv: Kibbutz Meuchad. [In Hebrew]

Talias, M. (1994). Environmental campaigns in Israel and their political-philosophical character. State, Government and International Relations, 39, 171-197. [In Hebrew]

Uekotter, F. (2010). In search of the lost environmental movement, or: Is the ecological movement a modern myth? Tabur-Yearbook for European history, society, culture and thought, 3, 19-37. [In Hebrew] 